3. Botelho R. Motivate Healthy Habits: Change Yourself Before Helping Others. Rochester, NY: MHH Publications; 2002.

4. Botelho R. Beyond Advice: 2. Developing Motivational Skills. Rochester, NY: MHH Publications; 2002.

5. Miller W/R, Rollnick S, Moyers TB. Motivational Interviewing. Professional Training Videotape Series. Albuquerque, NM: Center on Alcoholism, Substance Abuse and Addictions, University of New Mexico; 1998.

6. Botelho R. Beyond Advice: 1. Becoming a Motivational Practitioner. Rochester, NY: MHH Publications; 2002.

7. Moyers TB, Martin T, Manuel JK, Miller WR. The Motivational Interviewing Treatment Integrity (MITI) Scale. Version 2.0. Albuquerque, NM: Center on Alcoholism, Substance Abuse and Addictions, University of New Mexico; 2003.

8. Baer JS, Rosengren DB, Dunn CW, Wells EA, Ogle RL, Hartzler B. An evaluation of workshop training in motivational interviewing for addiction and mental health clinicians. Drug Alcohol Depend. 2004;73:99-106.
9. Glasgow RE, Vogt TM, Boles SM. Evaluating the public health impact of health promotion interventions: the RE-AIM framework. Am J Public Health. 1999;89:1322-1327.

10. Glasgow RE, Lichtenstein E, Marcus AC. Why don't we see more translation of health promotion research to practice? Rethinking the efficacyto-effectiveness transition. Am J Public Health. 2003;93:1261-1267.

11. Miller WR, Mount KA. A small study of training in motivational interviewing: does one workshop change clinician and client behavior? Behav Cogn Psychother. 2001;29:457-471.

12. Lane C, Huws-Thomas M, Hood K, Rollnick S, Edwards K, Robling $M$. Measuring adaptations of motivational interviewing: the development and validation of the behavior change counseling index (BECCI). Patient Educ Couns. 2005;56:166-173.

\title{
Wellness for a Lifetime: Improving Lifestyle Behaviors of Low-Income, Ethnically Diverse Populations
}

\author{
Laura Anderko, PbD, RN, Claudia Bartz, PbD, RN, FAAN, Sally Lundeen, PbD, RN, FAAN \\ University of Wisconsin-Milwaukee College of Nursing, Milwaukee, Wis \\ Ann Fam Med 2005;3(Suppl 2):S35-S36. DOI: 10.1370/afm.318. \\ Conflicts of interest: none reported
}

CORRESPONDING AUTHOR

Laura Anderko, PhD, RN, University of Wisconsin-Milwaukee College of Nursing, PO Box 413, Milwaukee, WI 53202-0413, landerko@uwm.edu

\section{PURPOSE}

$\mathrm{E}$ ight community nursing centers (CNCs) belonging to the Midwest Nursing Centers Consortium, a practice-based research network, implemented a community-based, multidimensional strategy to promote behavior changes among high-risk, ethnically diverse, low-income adults. The purposes of this study were (1) to promote increased physical activity levels and improved nutrition among CNC clients, and (2) to assess clinician evaluation and referral behaviors regarding clients' physical activity and nutrition. This article describes key lessons learned from this study.

\section{METHODS}

The study used a time-series design across the 8 CNCs. The study was grounded in a community-based, public health framework, thus encouraging community outreach for participant recruitment. Clients were recruited for a 16-week course titled Wellness for a Lifetime. The course materials were based on a 10 -week pilot project recently completed by one of the CNCs. These materi- als, developed by a multidisciplinary team using health behavior theory ${ }^{1}$ and culturally appropriate content, were provided to each $\mathrm{CNC}$ and outlined didactic course content, as well as themes used for discussion during the support group sessions. Didactic topics included food categories and nutritional content; principles of stretching and exercising; relationship of disease, such as hypertension, to diet and activity; and methods of stress reduction. Participants practiced safe exercises and used workout plans and walking routes. Support sessions included discussion of challenges and successes related to behavior changes, as well as field trips to fast-food restaurants and grocery stores to learn how to determine the nutritional content of a variety of food items.

Data were collected and analyzed from (1) chart audits (preintervention and postintervention) to assess change by advanced practice nurses (APNs) in documentation of assessments and in referrals for clients' nutrition and physical activity; (2) end-of-program telephone interviews of APNs at the 8 sites to identify barriers to recruitment and retention, and strengths of the program from the clinicians' point of view; (3) weekly and end-ofcourse participant satisfaction surveys that included self- 
reported changes related to diet and physical activity and, helpfulness of a health buddy; and (4) preintervention and postintervention assessment of clients' knowledge and behaviors related to diet and physical activity.

\section{LESSONS LEARNED}

CNCs provide a model of primary care delivery that merges traditional medical management with primary prevention and community-based health promotion strategies. ${ }^{2}$ One important lesson learned with this study was that CNCs vary considerably in their delivery of primary care. For example, fewer participants were recruited by $\mathrm{CNC}$ that used a more traditional primary care model, wherein the community of service is narrowly defined as registered clinic clients and the point of entry to service typically occurs at clinic registration. CNCs were more successful in recruiting clients (1) when they were housed within community-based organizations and the point of entry for services was determined by community residents, and (2) when service provision routinely included a primary prevention focus in addition to traditional primary health care. Although all clinicians, and thus recruiters, for this study were APNs, their style of work was necessarily related to the practice milieu for their CNC. Those who were in a traditional primary care setting, whether in a freestanding community or hospital-based location, considered potential participants as they came to the center for care. Those APNs who were in nontraditional settings, located in and integrated as a part of existing community-based organizations, such as local neighborhood centers, anticipated that potential clients would be coming to the site for a variety of reasons, for example, to use a food bank, clothing closet, or daycare center at the facility, which expanded the pool of study clients at these CNCs.

A second lesson learned was the need to consider the possibility of continuing these services beyond the designated 16-week project time frame. The success of the project across the sites created an overwhelming response by the communities to continue the services long term. The community-based CNCs, where services are continuous and a great emphasis is placed on the coordination of all health and health-related services (encompassing primary, secondary, and tertiary levels of prevention), would be more able to continue, for example, a weekly session on healthy diet and physical activity as part of their standard programming. CNCs using a more traditional primary care model, wherein the individual is seen as the unit of service and services are seen as episodic, would be less able to continue an "additional" education program, such as Wellness for a Lifetime.

A third lesson learned involved the challenge of ensuring consistent data gathering and interventions across 8 sites in 5 states to obtain comparable data for analysis. Although the Wellness for a Lifetime manual was used consistently across the sites, each site's nurse-educator modified her approach based on the specific needs of the population (eg, Spanish-speaking groups, elderly groups). Ongoing video-teleconferences, telephone, and e-mail consultations were necessary for communicating across geographically distant sites, but were not sufficient to ensure true reliability. It would have been preferable for the principal investigator, the project director, or both to visit all study sites periodically to ensure greater reliability and validity of study implementation. Ideally, visits should take place before and during the intervention period on a regularly scheduled basis.

\section{CONCLUSIONS}

Health disparities experienced by populations served by CNCs warrant continued community-based primary health care research. From this study, we know that research plans must take into consideration the model of health care delivery of CNCs to ensure sufficient subject recruitment and retention. Also, communitybased primary health care research is relatively new, with few tested instruments and with clinicians, staff, and subject populations generally unfamiliar with the research process; this fact requires great attention to detail to ensure that study is reliable and valid that the results are generalizable. Multisite studies in primary health care require strong commitment from the health care community, sufficient funding for research support, and most importantly, collaboration with community residents to achieve successful outcomes.

To read or post commentaries in response to this article, see it online at http://www.annfammed.org/cgi/content/full/3/Suppl_2/S35.

Key words: Practice-based research network; health education; health behavior; diet; exercise; low-income population

Submitted December 21, 2004; submitted, revised, March 9, 2005; accepted March 16, 2005.

Funding support: This work was supported by Prescription for Health, a national program of The Robert Wood Johnson Foundation with support from the Agency for Healthcare Research and Quality.

Acknowledgments: The following coinvestigators are warmly acknowledged for this study: Jean Bell Calvin, RN, MS; Kathy Dontje, RN, MSN; Kathryn Fiandt, RN, DNS; Elizabeth Kinion, RN, EdD; Elaine McIntosh, RN, MS; Rochelle Nelson, RN, MS; Donna Plonczynski, RN, PhD; Joanne Pohl, RN, PhD; and Pat Schafer, RN, PhD.

\section{References}

1. Rosenstock IM, Strecker VJ, Becker MH. Social learning theory and the health belief model. Health Educ Q. 1988;15:175-183.

2. Lundeen SP. An alternative paradigm for promoting health in communities: the Lundeen Community Nursing Center Model. Fam Comm Health. 1999;21:15-28. 